\title{
Training in élite young athletes (the training of young athletes (TOYA) study): injuries, flexibility and isometric strength*
}

\author{
Nicola Maffulli MD PhD MIBiol, John B. King FRCS ${ }^{+}$and Peter Helms PhD FRCP \\ The Institute of Child Health, Respiratory and Anaesthetic Unit, Sports Medicine Laboratory, London, UK and \\ tThe Royal London Hospital Medical College, Department of Orthopaedics, Whitechapel, London, UK
}

\begin{abstract}
Using a mixed longitudinal design, the incidence of injuries, and the development of flexibility and isometric strength of the upper and lower limbs were studied for 2 years in 453 élite young athletes (aged between 9 and 18 years) practising football, gymnastics, swimming or tennis. The children suffered from a low incidence of injuries. Strength and flexibility did not exert a significant role in determining injuries. The rate of injury was not significantly different between the 2 years of the study. Young swimmers showed a greater generalized flexibility. Girls were more flexible than boys between the ages of 13 to $\mathbf{1 6}$ years. Athletic children are able to exert greater isometric strength than normal schoolchildren. Boys diverged from the normal population at 14 years, while athletic girls were stronger at all ages. Girls were stronger than boys up to age 12, who were still increasing their muscle strength at 19 years. The average maximal isometric strength exerted in both upper and lower limbs in the four sports was not significantly different. Male gymnasts over 11 years old were significantly stronger than all other athletes.
\end{abstract}

Keywords: Exercise, growth, sport, anthropometry

Competitive sports participation in youngsters has become an established feature of the western world $^{1-3}$. However, 3 to $11 \%$ of school-aged children are injured each year while taking part in some form of sports activity ${ }^{4,5}$, with boys affected twice as much as girls ${ }^{6}$. The large differences among researchers and sports in the incidence of injuries among sporting youngsters may be due to several reasons, such as the different definition of injury, the nature of the study (retrospective or prospective), the data collection system, the exposure to the various sports, and the level at which the sport was practised ${ }^{1-3}$.

Flexibility is an important factor both in human athletic performance 7,9 and in many traumatic and

\footnotetext{
*The work reported in this article is part of the thesis for the degree of Doctor of Philosophy completed by Nicola Maffulli at the University of London, UK, in March 1992
}

Address for correspondence: N. Maffulli, Department of Orthopaedic Surgery, University of Aberdeen Medical School, Foresterhill, Aberdeen AB9 2ZD, UK

(C) 1994 Butterworth-Heinemann Ltd 0306-3674/94/020123-14 orthopaedic conditions ${ }^{10-12}$. Some reports have claimed a strong association ${ }^{13,14}$ between injuries and hypermobile joints, while according to others ligamentous laxity does not increase this risk 9 . Some groups of athletes, such as ballet dancers, may exhibit imbalanced flexibility ${ }^{7}$, which could predispose them to painful snapping hip and trochanteric bursitis ${ }^{15}$.

The degree and distribution of flexibility in athletes may be important in the genesis and presentation of injuries ${ }^{14}$, as flexibility can be specific to each side of the body even in the same joint ${ }^{16}$. Pubertal staging ${ }^{17}$ has greater predictive value than chronological age ${ }^{18}$, with no evidence of a relative decrease in flexibility during the period of maximal linear growth.

Few normative data are available on the development of muscle strength ${ }^{19-24}$. Up to age 13, there are no significant differences between the sexes, with a clear dissociation in favour of boys thereafter ${ }^{22}$. The observed sex difference for absolute strength when expressed as ratios of body mass or lean body mass ${ }^{19}, 20,23,25$ become less evident when normalized per unit of muscle cross-sectional area ${ }^{23}$ or muscle and bone combined ${ }^{25}$.

In non-athletic schoolchildren, the strength of both the upper and lower limb rises steadily starting from the age of 8-12 years, with a further rapid increase in strength in both the knee extensors and elbow flexors in boys even after the end of longitudinal and ponderal growth ${ }^{26}$. Hormonal influences may explain the dissociation in strength between boys and girls at puberty ${ }^{24}$.

We report part of the results of a mixed longitudinal study on the effects of physical training on the musculoskeletal system, focusing on injuries, flexibility and isometric strength of the upper and lower limb.

\section{Subjects and methods}

\section{Recruitment of subjects}

Young athletes were randomly selected from a coach-nominated sample from within a 300-mile radius of London. Football, gymnastics, swimming and tennis were represented. Both sexes were represented except in football. The study was 
Training in élite young athletes: N. Maffulli, J. B. King and P. Helms

Table 1. Age distribution by sport

\begin{tabular}{lccccc}
\hline Cohort & $\begin{array}{c}\text { Age } \\
\text { (years) }\end{array}$ & Football & Gymnastics & Swimming & Tennis \\
\hline Year $1^{*}$ & & & & & \\
1971 & 17 & 12 & 20 & 24 & 26 \\
1973 & 15 & 25 & 28 & 30 & 32 \\
1975 & 13 & 28 & 28 & 30 & 37 \\
1977 & 11 & - & 21 & 30 & 39 \\
1979 & 9 & - & 22 & - & 21 \\
Total & & 65 & 119 & 114 & 155 \\
& & & & & \\
\hline Year $2^{+}$ & 18 & 10 & 18 & 22 & 25 \\
1971 & 16 & 23 & 18 & 27 & 29 \\
1973 & 14 & 25 & 23 & 27 & 35 \\
1975 & 12 & - & 20 & 28 & 35 \\
1977 & 10 & - & 20 & - & 21 \\
1979 & & 58 & 99 & 104 & 145 \\
Total & & & & & \\
\hline
\end{tabular}

*Total sample, $453 ;{ }^{\dagger}$ Total sample, 406 approved by the Ethical Committee of the Institute of Child Health, University of London.

The age at which the youngest child entered the study differed according to the requirements of each sport. The basic criterion for inclusion in the study was that the children showed performance success, of at least county standard, in the year before being nominated.

A database was developed for each sport, birth year and gender group. A random selection for each sport, birth year and gender group was achieved using a computer generated list. A short questionnaire was sent to the children and parents who refused to take part, asking for the number of hours trained and parental occupation. Comparing information from this group with data from families who agreed to take part established that there was no significant difference either in training time or social class. The study had a representative sample of successful young athletes. The social class composition

Table 2. Gender distribution

\begin{tabular}{|c|c|c|c|c|c|c|c|c|c|c|c|c|c|c|}
\hline \multirow[b]{3}{*}{ Sport } & \multicolumn{7}{|c|}{ Year 1} & \multicolumn{7}{|c|}{ Year 2} \\
\hline & \multirow[b]{2}{*}{ Gender } & \multicolumn{5}{|c|}{ Age (years) } & \multirow[b]{2}{*}{ Total } & \multirow[b]{2}{*}{ Gender } & \multicolumn{5}{|c|}{ Age (years) } & \multirow[b]{2}{*}{ Total } \\
\hline & & 17 & 15 & 13 & 11 & 9 & & & 18 & 16 & 14 & 12 & 10 & \\
\hline Football & $M$ & 12 & 25 & 28 & - & - & 65 & $M$ & 10 & 23 & 25 & - & - & 58 \\
\hline \multirow{2}{*}{ Gymnastics } & $F$ & 13 & 18 & 18 & 15 & 17 & 81 & $F$ & 12 & 12 & 16 & 15 & 16 & 71 \\
\hline & $M$ & 7 & 10 & 10 & 6 & 5 & 38 & $M$ & 6 & 6 & 7 & 5 & 4 & 28 \\
\hline \multirow[t]{2}{*}{ Swimming } & $\mathrm{F}$ & 14 & 16 & 15 & 15 & - & 60 & $\mathrm{~F}$ & 12 & 15 & 15 & 14 & - & 56 \\
\hline & M & 10 & 14 & 15 & 15 & - & 54 & $M$ & 10 & 12 & 12 & 14 & - & 48 \\
\hline \multirow[t]{2}{*}{ Tennis } & $\mathrm{F}$ & 14 & 17 & 19 & 20 & 11 & 81 & $F$ & 14 & 15 & 18 & 17 & 11 & 75 \\
\hline & $M$ & 12 & 15 & 18 & 19 & 10 & 74 & $M$ & 11 & 14 & 16 & 19 & 10 & 70 \\
\hline Total & & & & & & & 453 & & & & & & & 406 \\
\hline
\end{tabular}

Table 3. Hours trained per week by boy footballers in years 1 and 2

\begin{tabular}{|c|c|c|c|c|c|c|c|c|c|c|}
\hline \multirow[b]{2}{*}{ Birth year } & \multicolumn{5}{|c|}{ Year 1} & \multicolumn{5}{|c|}{ Year 2} \\
\hline & No. & Age* (years) & Min & $\operatorname{Max}$ & Mean & No. & Age $^{*}$ (years) & Min & $\operatorname{Max}$ & Mean \\
\hline 1975 & 28 & $12.8(0.3)$ & 0:00 & $8: 30$ & $2: 18$ & 25 & $13.9(0.3)$ & 0:00 & 9:00 & 4:10 \\
\hline 1973 & 25 & $14.9(0.4)$ & $1: 45$ & $8: 30$ & $4: 32$ & 23 & $15.9(0.4)$ & $2: 30$ & $25: 00$ & $7: 03$ \\
\hline 1971 & 12 & $16.9(0.2)$ & 0:00 & $24: 30$ & 9:12 & 10 & $18.0(0.2)$ & 4:00 & $34: 00$ & $10: 39$ \\
\hline
\end{tabular}

*Values are mean(s.d.)

Table 4. Hours trained per week by boy gymnasts in years 1 and 2

\begin{tabular}{|c|c|c|c|c|c|c|c|c|c|c|}
\hline \multirow[b]{2}{*}{ Birth year } & \multicolumn{5}{|c|}{ Year 1} & \multicolumn{5}{|c|}{ Year 2} \\
\hline & No. & Age* (years) $^{*}$ & Min & $\operatorname{Max}$ & Mean & No. & Age $^{*}$ (years) & Min & Max & Mean \\
\hline 1979 & 5 & $9.2(0.3)$ & $2: 30$ & 14:00 & $7: 33$ & 4 & $10.3(0.2)$ & $2: 30$ & 17:00 & $7: 41$ \\
\hline 1977 & 6 & $11.4(0.3)$ & $10: 00$ & $17: 30$ & $12: 55$ & 5 & $12.3(0.3)$ & $11: 00$ & $30: 00$ & $17: 00$ \\
\hline 1975 & 10 & $13.1(0.3)$ & $8: 30$ & $22: 30$ & $14: 25$ & 7 & 14.1(0.3) & $11: 45$ & $30: 00$ & $17: 42$ \\
\hline 1973 & 10 & $15.2(0.4)$ & $8: 30$ & 20:00 & $14: 43$ & 6 & $16.1(0.2)$ & $5: 30$ & $17: 00$ & $13: 30$ \\
\hline 1971 & 7 & $17.1(0.4)$ & $8: 30$ & 29:00 & $17: 20$ & 6 & $17.9(0.2)$ & $5: 00$ & $27: 30$ & $15: 07$ \\
\hline
\end{tabular}

*Values are mean(s.d.) 
of parents of the children taking part in the study is shown in Figure 1.

Based on 576 initial aproaches, the acceptance rates for each sport were: football: $69 \%$; gymnasts: $88 \%$; swimming: $83 \%$; tennis: $75 \%$.

\section{Hours trained}

The number of hours trained per week by age and sport in the 2 years of the study is shown in Tables 3 to 9.

\section{Attrition}

At the end of the second year, 51 children (11\%) had dropped out of the study (Table 10), and 55 had retired from their sport (Table 11).

\section{Growth and development}

All anthropometric measurements were performed by two trained measurers using a Harpenden Stadiometer (Holtain, Crosswell, UK), a Holtain anthropometer, a non-extensible CMS steel measur-

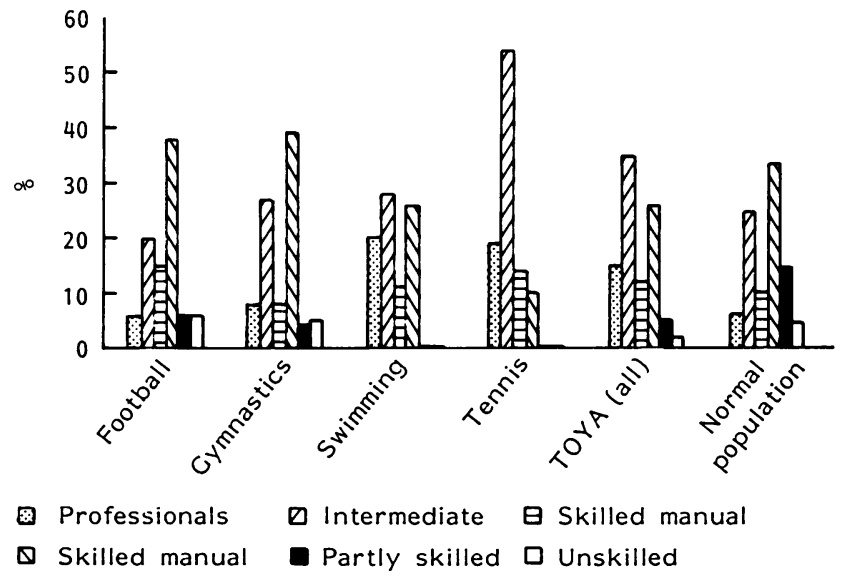

Figure 1. Social class distribution in the TOYA study

ing-tape (CMS Weighing Equipment, London, UK), a Holtain skinfold caliper, a Soehnle electronic scale accurate to $100 \mathrm{~g}$ (Soehnle, Bonn, Germany), and a sitting-height box $50 \mathrm{~cm}$ tall. All measurements were

Table 5. Hours trained per week by girl gymnasts in years 1 and 2

\begin{tabular}{|c|c|c|c|c|c|c|c|c|c|c|}
\hline \multirow[b]{2}{*}{ Birth year } & \multicolumn{5}{|c|}{ Year 1} & \multicolumn{5}{|c|}{ Year 2} \\
\hline & No. & Age $^{*}$ (years) & Min & Max & Mean & No. & Age $^{*}$ (years) & Min & Max & Mean \\
\hline 1979 & 17 & $9.4(0.3)$ & $5: 00$ & $21: 00$ & $11: 27$ & 16 & $10.4(0.3)$ & $4: 30$ & $23: 30$ & $11: 33$ \\
\hline 1977 & 15 & $11.1(0.3)$ & 4:00 & $20: 30$ & $12: 28$ & 15 & $12.1(0.3)$ & $7: 30$ & $22: 45$ & $12: 34$ \\
\hline 1975 & 18 & $13.0(0.3)$ & $6: 30$ & 23:00 & $13: 29$ & 16 & $14.0(0.3)$ & $6: 45$ & $24: 15$ & $13: 55$ \\
\hline 1973 & 18 & $15.2(0.3)$ & $8: 00$ & 23:00 & $16: 14$ & 12 & $16.2(0.5)$ & $10: 00$ & $28: 45$ & $13: 55$ \\
\hline 1971 & 13 & $17.1(0.4)$ & 4:00 & 21:00 & $13: 25$ & 12 & $18.2(0.4)$ & $5: 30$ & $20: 00$ & $13: 21$ \\
\hline
\end{tabular}

*Values are mean(s.d.)

Table 6. Hours trained per week by boy swimmers in years 1 and 2

\begin{tabular}{|c|c|c|c|c|c|c|c|c|c|c|}
\hline \multirow[b]{2}{*}{ Birth year } & \multicolumn{5}{|c|}{ Year 1} & \multicolumn{5}{|c|}{ Year 2} \\
\hline & No. & Age* (years) & Min & Max & Mean & No. & Age* (years) $^{*}$ & Min & $\operatorname{Max}$ & Mean \\
\hline 1977 & 15 & $11.1(0.2)$ & $2: 30$ & $15: 45$ & $7: 17$ & 14 & $12.2(0.3)$ & 4:00 & $17: 45$ & $11: 22$ \\
\hline 1975 & 15 & $13.1(0.3)$ & $1: 00$ & $18: 55$ & $10: 24$ & 12 & $14.0(0.3)$ & 1:00 & $20: 00$ & $11: 25$ \\
\hline 1973 & 14 & $15.0(0.2)$ & $3: 30$ & $22: 30$ & 13:02 & 12 & $16.0(0.2)$ & $3: 30$ & $22: 30$ & $12: 59$ \\
\hline 1971 & 10 & $16.9(0.2)$ & $7: 45$ & 18:00 & $11: 49$ & 10 & $17.9(0.2)$ & $2: 30$ & $16: 30$ & $10: 47$ \\
\hline
\end{tabular}

*Values are mean(s.d.)

Table 7. Hours trained per week by girl swimmers in years 1 and 2

\begin{tabular}{|c|c|c|c|c|c|c|c|c|c|c|}
\hline \multirow[b]{2}{*}{ Birth year } & \multicolumn{5}{|c|}{ Year 1} & \multicolumn{5}{|c|}{ Year 2} \\
\hline & No. & Age* $^{*}$ (years) & $\operatorname{Min}$ & Max & Mean & No. & Age $^{*}$ (years) & Min & $\operatorname{Max}$ & Mean \\
\hline 1977 & 15 & $11.1(0.3)$ & $3: 0$ & $13: 45$ & $7: 27$ & 14 & $12.1(0.3)$ & $2: 45$ & $20: 45$ & $11: 17$ \\
\hline 1975 & 15 & $13.0(0.3)$ & $0: 00$ & $15: 45$ & 9:05 & 15 & $13.9(0.3)$ & 0:00 & $20: 45$ & $10: 54$ \\
\hline 1973 & 16 & $15.7(0.7)$ & $6: 15$ & $22: 30$ & $13: 22$ & 15 & $16.1(0.3)$ & 0:00 & $22: 30$ & $13: 35$ \\
\hline 1971 & 14 & $17.0(0.4)$ & $6: 25$ & $22: 30$ & $15: 23$ & 12 & $18.0(0.4)$ & $5: 45$ & $23: 45$ & $13: 39$ \\
\hline
\end{tabular}

*Values are mean(s.d.) 
Training in élite young athletes: N. Maffulli, J. B. King and P. Helms

Table 8. Hours trained per week by boy tennis players in years 1 and 2

\begin{tabular}{|c|c|c|c|c|c|c|c|c|c|c|}
\hline \multirow[b]{2}{*}{ Birth year } & \multicolumn{5}{|c|}{ Year 1} & \multicolumn{5}{|c|}{ Year 2} \\
\hline & No. & Age* (years) $^{*}$ & Min & $\operatorname{Max}$ & Mean & No. & Age* (years) & Min & $\operatorname{Max}$ & Mean \\
\hline 1979 & 11 & $9.7(0.3)$ & $1: 30$ & 8:00 & $4: 19$ & 10 & $10.6(0.3)$ & 5:00 & $12: 00$ & $9: 12$ \\
\hline 1977 & 19 & $11.0(0.3)$ & 4:00 & $11: 00$ & $7: 08$ & 19 & $12.0(0.4)$ & $2: 30$ & $18: 30$ & $8: 43$ \\
\hline 1975 & 18 & $13.0(0.3)$ & $3: 45$ & 19:00 & $9: 48$ & 16 & $14.0(0.2)$ & 5:00 & $25: 00$ & $13: 48$ \\
\hline 1973 & 15 & $14.9(0.4)$ & $2: 45$ & $18: 30$ & $8: 47$ & 14 & $15.9(0.4)$ & $2: 45$ & 19.20 & $11: 43$ \\
\hline 1971 & 12 & $16.9(0.3)$ & $6: 00$ & $34: 00$ & $17: 30$ & 11 & $18: 1(0.4)$ & 4:00 & 25:00 & $14: 27$ \\
\hline
\end{tabular}

*Values are mean(s.d.)

Table 9. Hours trained per week by girl tennis players in years 1 and 2

\begin{tabular}{|c|c|c|c|c|c|c|c|c|c|c|}
\hline \multirow[b]{2}{*}{ Birth year } & \multicolumn{5}{|c|}{ Year 1} & \multicolumn{5}{|c|}{ Year 2} \\
\hline & No. & Age $^{*}$ (years) & Min & $\operatorname{Max}$ & Mean & No. & Age $^{*}$ (years) & Min & $\operatorname{Max}$ & Mean \\
\hline 1979 & 11 & $9.7(0.3)$ & 1:00 & $10: 30$ & $5: 29$ & 11 & $10.7(0.3)$ & $2: 00$ & $7: 40$ & $5: 25$ \\
\hline 1977 & 20 & $11.1(0.4)$ & $1: 00$ & $16: 15$ & $5: 22$ & 17 & $12.2(0.4)$ & 3:00 & $24: 30$ & 8:05 \\
\hline 1975 & 19 & $12.9(0.4)$ & 4:00 & $17: 45$ & 9:01 & 18 & $13.9(0.4)$ & 6:00 & 19:00 & $10: 32$ \\
\hline 1973 & 17 & $14.9(0.3)$ & $3: 00$ & $29: 45$ & $10: 16$ & 15 & 16.1(0.4) & $3: 00$ & $13: 30$ & $7: 44$ \\
\hline 1971 & 14 & $17.0(0.4)$ & 1.30 & $23: 30$ & $8: 58$ & 14 & 18.1(0.4) & $3: 30$ & $26: 30$ & $10: 41$ \\
\hline
\end{tabular}

*Values are mean(s.d.)

performed according to Tanner and Whitehouse ${ }^{27,28}$, using the system of decimal age ${ }^{29}$. The anthropometric variables measured were: standing height, sitting height and subischial leg length, body mass, pubertal status (assessing the stages of genitalia (penis) and breast development, and of pubic hair development

Table 10. Number of children who have withdrawn from this study

\begin{tabular}{lcccc}
\hline Cohort & Football & Gymnastics & Swimming & Tennis \\
\hline 1971 & 2 & 2 & 2 & 1 \\
1973 & 2 & 10 & 4 & 4 \\
1975 & 3 & 5 & 3 & 3 \\
1977 & - & 1 & 2 & 5 \\
1979 & - & 2 & - & - \\
Total & 7 & 20 & 11 & 13 \\
\hline
\end{tabular}

Table 11. Number of children who had retired from their sport

\begin{tabular}{|c|c|c|c|c|c|c|}
\hline \multirow[b]{2}{*}{ Cohort } & \multicolumn{3}{|c|}{ Girls } & \multicolumn{3}{|c|}{ Boys } \\
\hline & $G$ & $S$ & $T$ & $F$ & $G$ & $S$ \\
\hline 1971 & 4 & 4 & 4 & - & - & 1 \\
\hline 1973 & 6 & 4 & - & 1 & 3 & 1 \\
\hline 1975 & 4 & 3 & 1 & - & 1 & 1 \\
\hline 1977 & 2 & 3 & - & - & 1 & - \\
\hline 1979 & 1 & - & - & - & - & - \\
\hline Total & 17 & 14 & 5 & 1 & 5 & 3 \\
\hline
\end{tabular}

F, football; G, gymnastics; S, swimming; T, tennis using standard rating of 1 to 5 , and the stages of axillary hair using standard rating of 1 to 3 ), upper arm circumference, and skinfolds (triceps, biceps, subscapular and suprailiac ${ }^{30,31}$ ). Skinfolds, limb circumferences and lengths were measured bilaterally. Results on height and body mass are given in Tables 12 to 15 .

The percentage of body fat was calculated from the above skinfolds ${ }^{32,33}$. Muscle and bone area of the upper arm (MBA) was calculated using the equation of de Koning et ll. $^{34}$.

Table 12. Standing height $(\mathrm{cm})^{*}$ and mass $(\mathrm{kg})^{*}$ in girls (year 1$)$

\begin{tabular}{lccc}
\hline Cohort & $N$ & Height & Mass \\
\hline Gymnasts & & & \\
1971 & 13 & $160.83(5.6)$ & $54.35(7.2)$ \\
1973 & 18 & $158.82(6.0)$ & $49.58(5.8)$ \\
1975 & 18 & $149.80(6.4)$ & $38.68(4.7)$ \\
1977 & 15 & $142.65(7.0)$ & $32.25(4.1)$ \\
1979 & 17 & $132.44(5.6)$ & $27.92(4.0)$ \\
Swimmers & & & \\
1971 & 14 & $166.96(5.9)$ & $56.90(6.9)$ \\
1973 & 16 & $167.11(4.7)$ & $56.99(6.9)$ \\
1975 & 15 & $159.53(5.6)$ & $49.91(6.5)$ \\
1977 & 15 & $147.76(8.5)$ & $39.49(8.3)$ \\
Tennis players & & & \\
1971 & 14 & $166.71(5.0)$ & $60.21(5.6)$ \\
1973 & 17 & $166.59(5.9)$ & $57.79(5.7)$ \\
1975 & 19 & $159.50(7.7)$ & $49.74(8.5)$ \\
1977 & 20 & $147.17(5.1)$ & $37.76(4.0)$ \\
1979 & 11 & $137.60(5.6)$ & $31.78(4.9)$ \\
\hline
\end{tabular}

*Values are mean(s.d.) 
Training in élite young athletes: N. Maffulli, J. B. King and P. Helms

Table 13. Standing height $(\mathrm{cm})^{*}$ and mass $(\mathrm{kg})^{*}$ in boys (year 1$)$

\begin{tabular}{lrcc}
\hline Cohort & $N$ & Height & Mass \\
\hline Football players & & & \\
1971 & 12 & $174.77(5.2)$ & $67.95(5.8)$ \\
1973 & 25 & $171.42(7.5)$ & $59.98(9.5)$ \\
1975 & 28 & $151.99(4.4)$ & $40.28(4.4)$ \\
Gymnasts & & & \\
1971 & 7 & $168.44(3.8)$ & $60.04(8.9)$ \\
1973 & 10 & $162.56(7.9)$ & $52.42(8.4)$ \\
1975 & 10 & $148.22(8.6)$ & $38.72(6.2)$ \\
1977 & 6 & $139.3(2.8)$ & $32.68(2.9)$ \\
1979 & 5 & $129.73(4.2)$ & $25.06(1.4)$ \\
Swimmers & & & \\
1971 & 10 & $181.68(5.3)$ & $72.61(7.7)$ \\
1973 & 14 & $175.26(4.8)$ & $62.83(5.1)$ \\
1975 & 15 & $158.38(7.5)$ & $45.97(7.6)$ \\
1977 & 15 & $145.00(4.1)$ & $35.99(4.8)$ \\
Tennis players & & & \\
1971 & 12 & $177.76(4.2)$ & $66.98(7.8)$ \\
1973 & 15 & $172.84(6.8)$ & $57.90(7.2)$ \\
1975 & 18 & $157.20(9.5)$ & $45.14(8.5)$ \\
1977 & 19 & $146.75(5.5)$ & $35.66(5.0)$ \\
1979 & 11 & $140.67(4.6)$ & $32.97(4.7)$ \\
\hline & & & \\
\hline
\end{tabular}

*Values are mean(s.d.)

Table 14. Standing height $(\mathrm{cm})^{*}$ and mass $(\mathrm{kg})^{*}$ in girls (year 2)

\begin{tabular}{llll}
\hline Cohort & $N$ & Height & Mass \\
\hline Gymnasts & & & \\
1971 & 12 & $161.43(5.2)$ & $55.70(4.7)$ \\
1973 & 12 & $159.79(6.3)$ & $52.48(6.0)$ \\
1975 & 16 & $154.10(6.2)$ & $42.97(4.9)$ \\
1977 & 15 & $148.17(7.3)$ & $36.43(4.8)$ \\
1979 & 16 & $167.44(6.5)$ & $30.94(5.6)$ \\
Swimmers & & & \\
1971 & 12 & $167.30(6.5)$ & $57.37(7.8)$ \\
1973 & 15 & $168.18(4.9)$ & $61.15(8.3)$ \\
1975 & 15 & $162.43(4.5)$ & $51.19(5.3)$ \\
1977 & 14 & $153.22(9.0)$ & $44.33(8.8)$ \\
Tennis players & & & \\
1971 & 14 & $166.68(5.2)$ & $60.75(5.4)$ \\
1973 & 15 & $168.31(6.7)$ & $60.06(4.2)$ \\
1975 & 18 & $163.18(6.3)$ & $54.21(8.4)$ \\
1977 & 17 & $152.99(6.5)$ & $41.58(4.4)$ \\
1979 & 11 & $143.90(4.9)$ & $36.06(4.8)$ \\
\hline
\end{tabular}

*Values are mean(s.d.)

\section{Injuries}

Definition

An injury was classified as acute or overuse ${ }^{35}$. Injuries were investigated using a standard questionnaire administered personally by NM to both the child and the accompanying parent or guardian at each visit.

\section{Occurrence of injuries}

Injuries were classified according to their occurrence as training, competition or induced by causes other than sports. The anatomical location of the injury was also recorded.
Table 15. Standing height $(\mathrm{cm})^{*}$ and mass $(\mathrm{kg})^{*}$ in boys (year 2$)$

\begin{tabular}{lccc}
\hline Cohort & $N$ & Height & Mass \\
\hline Football players & & & \\
1971 & 10 & $176.39(4.1)$ & $69.33(5.1)$ \\
1973 & 23 & $175.95(6.8)$ & $66.45(9.0)$ \\
1975 & 25 & $158.41(5.2)$ & $46.15(5.0)$ \\
Gymnasts & & & \\
1971 & 6 & $171.12(2.4)$ & $62.82(5.9)$ \\
1973 & 6 & $166.40(8.8)$ & $57.52(9.0)$ \\
1975 & 7 & $154.88(11.3)$ & $44.43(8.3)$ \\
1977 & 5 & $143.33(3.4)$ & $35.14(3.2)$ \\
1979 & 4 & $132.57(4.1)$ & $27.42(1.9)$ \\
Swimmers & & & \\
1971 & 10 & $182.92(5.5)$ & $76.85(8.3)$ \\
1973 & 12 & $178.17(4.6)$ & $68.00(4.4)$ \\
1975 & 12 & $165.97(7.9)$ & $52.67(7.4)$ \\
1977 & 14 & $150.32(5.2)$ & $40.65(6.3)$ \\
Tennis players & & & \\
1971 & 11 & $179.34(3.9)$ & $70.74(8.2)$ \\
1973 & 14 & $178.21(5.7)$ & $65.26(7.6)$ \\
1975 & 16 & $163.23(10.8)$ & $50.45(10.1)$ \\
1977 & 19 & $151.56(5.8)$ & $39.56(6.7)$ \\
1979 & 10 & $145.34(5.1)$ & $36.78(4.7)$ \\
\hline
\end{tabular}

*Values are mean(s.d.)

\section{Flexibility}

Linear measures of flexibility were used ${ }^{36-38}$ (Figure 2). All the tests described were performed after a brief warm up, consisting of gentle stretching exercises. Two attempts were allowed each test, the best of which was used in subsequent analysis.

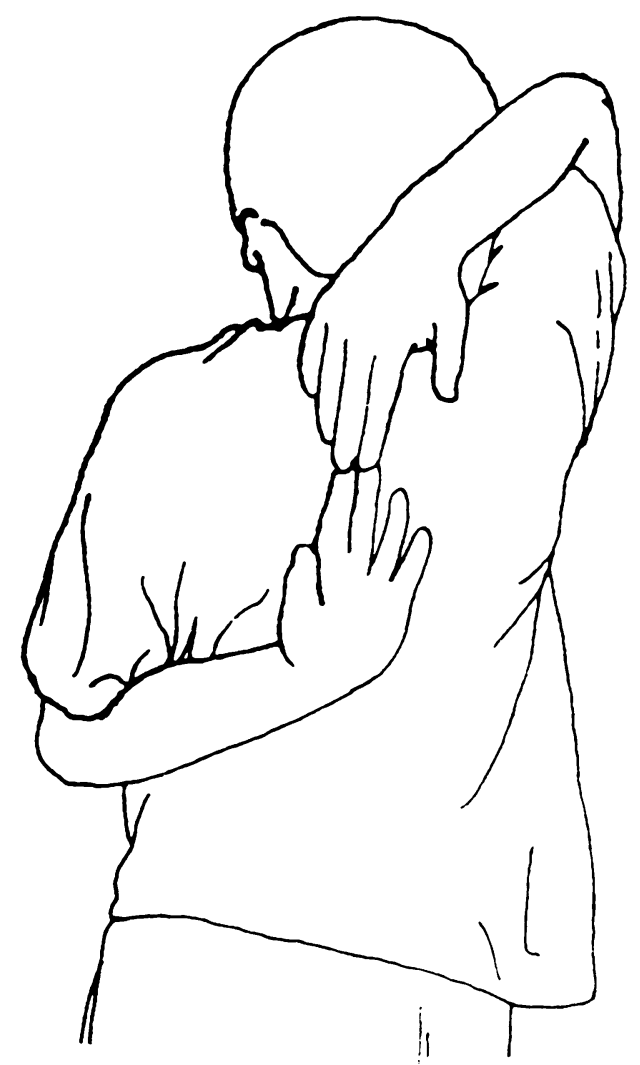

Figure 2. Method used to measure the flexibility of the upper limb and glenohumeral joint 


\section{Strength}

The muscle groups tested were the left elbow flexors and the left knee extensors ${ }^{39}$. Maximum isometric voluntary contraction (MIVC) strength was measured using a custom-made chair ${ }^{40}$ equipped with a compact portable gauge ${ }^{21}$ (Figure 3). The gauges were incorporated into an inextensible link (cable and webbing) which connected a cuff around the limb to be tested, and a fixed point about which the link could swivel. When energized with $5 \mathrm{~V}$, and the output amplified on an amplifier-recorder (Model 88182202 09, Series 552; Gould, Lyon, France), the gauges gave a linear response to force over the range 73.5-1200 Newtons. The apparatus was calibrated at least every week by suspending known weights, ranging from 7.5 to $119.6 \mathrm{~kg}$ (73.5-1200 Newtons), from the strain gauge.

\section{Testing procedure}

After introduction to the procedure, each child was asked to produce four maximal MIVC for each limb tested $^{21,41}$.

\section{Data analysis}

The data were stored in R:Base on an IBM-compatible $\mathrm{PC}$, and analysed using the SAS ${ }^{42}$ and the Systat ${ }^{43}$ statistical packages, installed on IBM compatible personal computers.

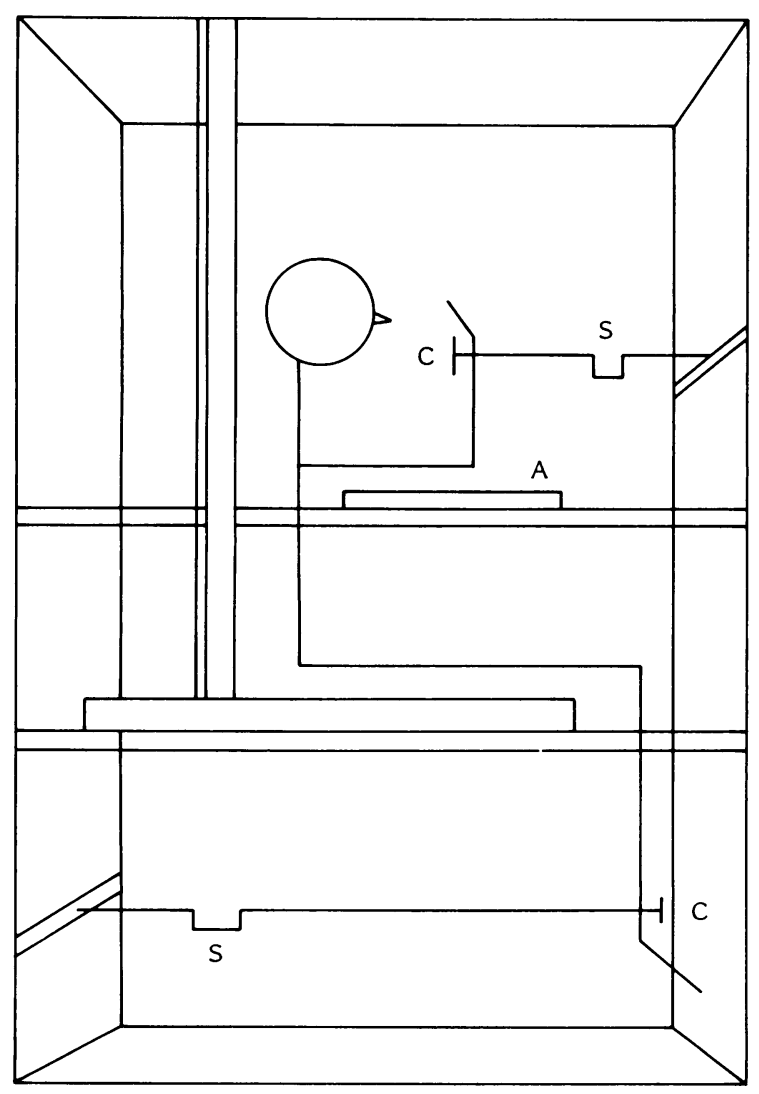

Figure 3. The apparatus used to measure isometric strength. A, adjustable shelf; $C$, cuff; $S$, strain gauge
Descriptive statistical analysis was carried out. Potential intra- and inter-cohort variations were tested for significance using analysis of variance (ANOVA) and analysis of covariance (ANCOVA), taking into account the effects of various covariates. Linear regression analysis was used to test the various relationships. Due to the number of primary analyses, the 0.03 level of significance was used to define a significant difference in order to minimize the possibility of a Type I interpretative error.

To identify the changing patterns of flexibility and strength development with age, data were plotted using a third order polynomial in order to minimize the residual sum of squares at each age ${ }^{43}$.

Although it has been common practice to express athletic performance as a ratio to a body variable, Tanner ${ }^{44}$ has shown that this approach may be misleading. Moreover, ratios are often treated as if they were means for single measures to compare groups ${ }^{44}$, hence the use of analysis of covariance in this study ${ }^{17,42,43}$.

\section{Results}

\section{Injuries}

The absolute total number of injuries remained constant at 229 in year 1 and 226 in year 2 . The injury rate increased from 0.50 to 0.55 injuries per year per child but this was not significant (Figures 4 and 5).

\section{Differences between sports}

The differences between the four sports in the frequency of injuries sustained during competition, training or outside their sport were only just statistically significant. Among the boys, footballers were more likely to be acutely injured during a match than in a training session, with a ratio of over $2: 1$. In gymnastics, the opposite was true.

\section{Location of injuries}

Both the acute and overuse injuries were grouped according to their location in trunk, upper limb and lower limb (Figure 6). The differences between the 2 years of the study were not statistically significant.

\section{Physiological characteristics and injuries}

The total injuries were considered as the sum of all the acute and of all the overuse injuries, and covariated for the amount of time spent training each week, the sport, the children's age and their gender. When the sums of all the acute and of all the overuse injuries were tested separately and combined, only modest, non-significant correlations were found in year 2 for the total number of injuries for the frontal splits and the left quadriceps strength. The children who suffered from none, one or more than two acute injuries were modestly different from each other for their frontal splits $(F=1.38 ; P=0.03)$.

The children suffering from none, one or more than two injuries to their trunk, upper limb or lower limb were not significantly different from each other. 


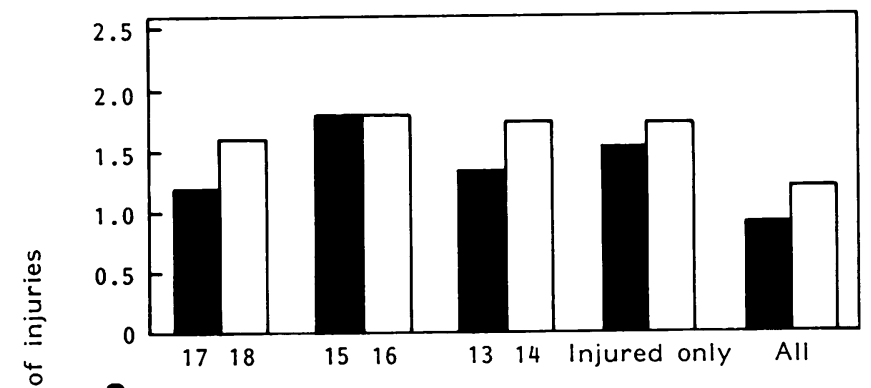

a

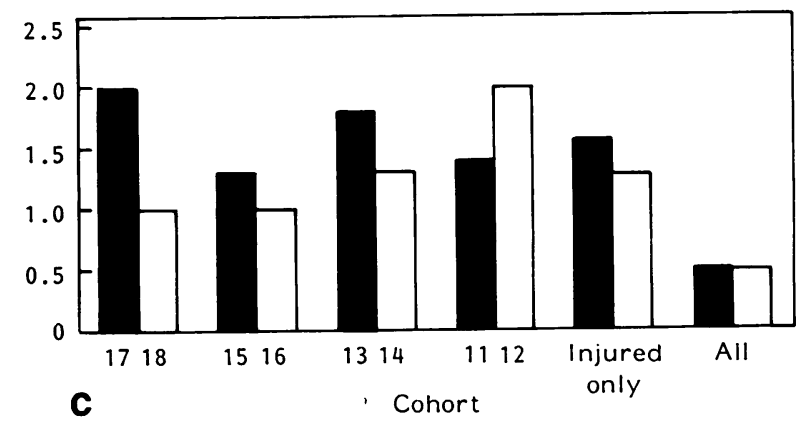

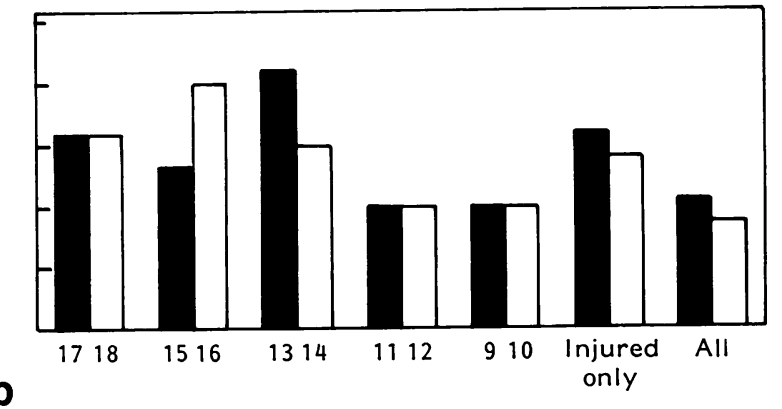

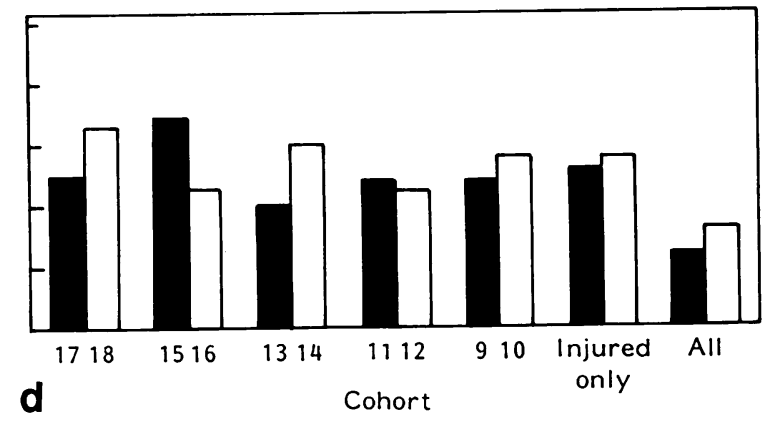

Figure 4. Incidence of injuries among boy athletes. The columns on the left show the rate incidence of injuries per injured child. The last column on the right shows the rate of incidence of injuries in all the sample, considering both injured and noninjured children: $\square$, year $1 ; \square$, year 2; a football; b gymnastics; c swimming; d tennis

\section{Flexibility}

Flexibility of the upper limb and glenohumeral joint Summary data of the flexibility of the right upper limb and glenohumeral joint for both sides and for all 453 children are presented in Figure 7.

Girls and boys appeared to be equally flexible at all ages. When covariated for cubit length, flexibility appeared to decrease after the age of 14 years $(P<0.01)$. Training time did not exert any significant effect for any sport.

The right side was more. flexible than the left in all sports and in both sexes (ANOVA; $P=0.005$ ). In both sexes, older gymnasts were the least flexible athletes, with swimmers being the most flexible (Figure 7).

Boy and girl gymnasts started by being at least as flexible as the other athletes, increasing the flexibility of their glenohumeral joints from 8 to 10 years. From 13 years, the boy gymnasts became remarkably less flexible (ANOVA; $P<0.03$ ).

\section{Flexibility of the lumbar spine and hamstrings}

ANOVA of the absolute values (Figure 8) showed that girls and boys were equally flexible up to age 12 years. Older children were significantly more flexible, with boys showing a significant decrease in trunk flexibility at 14 years with no such finding evident in girls (Figure 8). Boy and girl gymnasts were the most flexible of the four groups of athletes, even at an early age (ANOVA; $P<0.001$ ).

Subischial leg length, cubit length and height were major factors in determining the value measured. Gymnasts were even more flexible than the other groups (ANCOVA; $P<0.005$ ). Swimmers fell between gymnasts, and footballers and tennis players.

Female athletes in all three sports increased their trunk flexibility with growth (Figure 9), and female
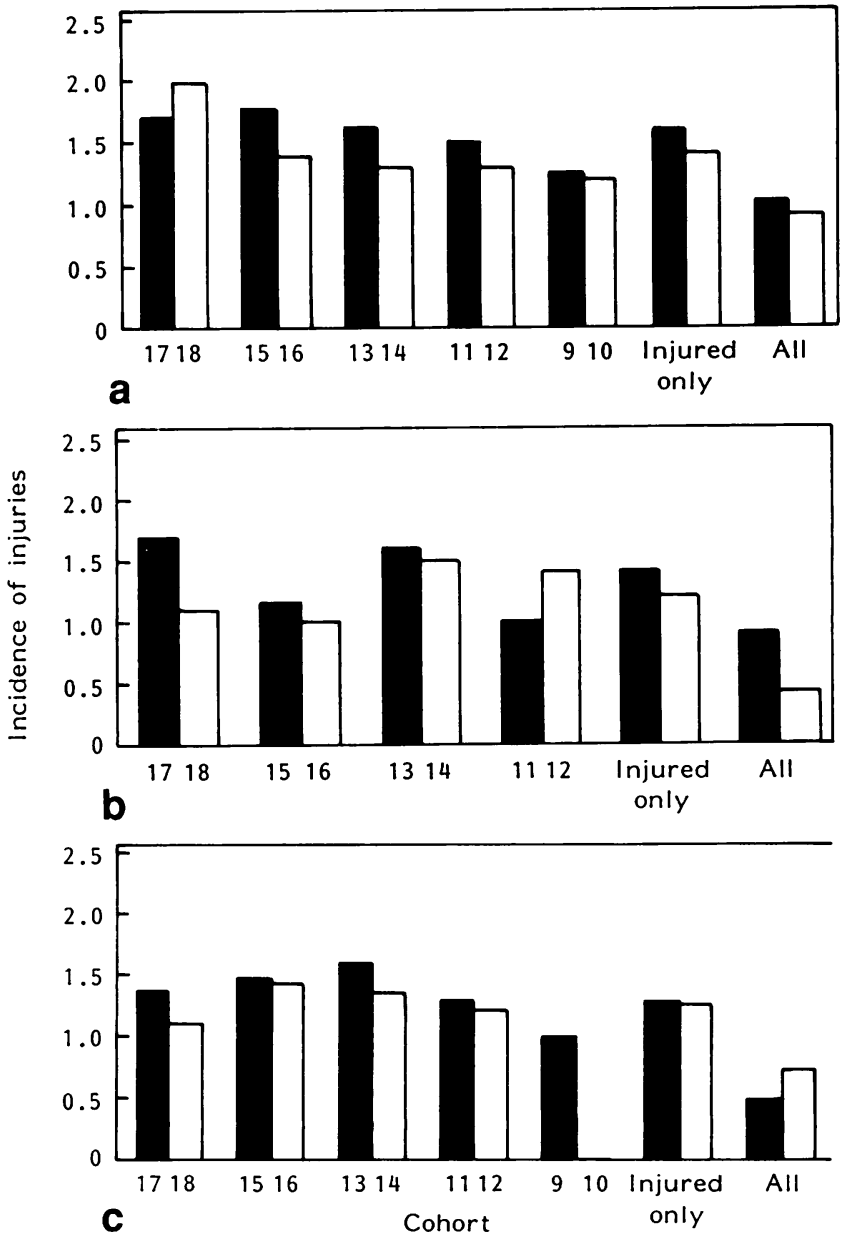

Figure 5. Incidence of injuries among girl athletes. The columns on the left show the rate of incidence of injuries per injured child. The last column on the right shows the rate of incidence of injuries in all the sample, considering both injured and non-injured children: $\square$, year $1 ; \square$, year 2; a gymnastics; b swimming; c tennis 


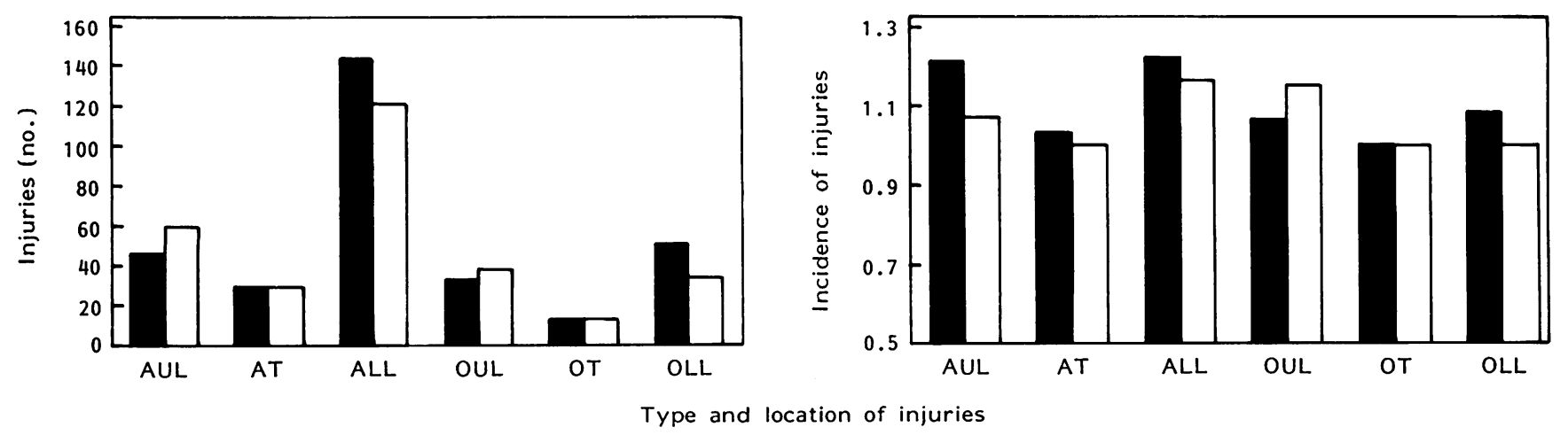

Figure 6. Acute and overuse injuries by location: AUL, acute injuries of the upper limb; AT, acute injuries of the trunk; ALL, acute injuries of the lower limb; OUL, overuse injuries of the upper limb; OT, overuse injuries of the trunk; OLL, overuse injuries of the lower limb; $\boldsymbol{a}$, year $1 ; \square$, year 2

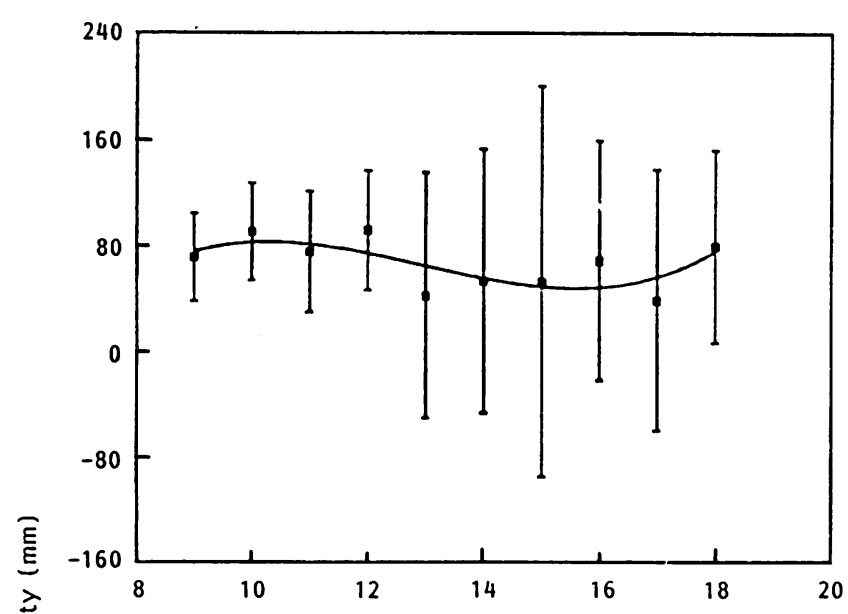

a

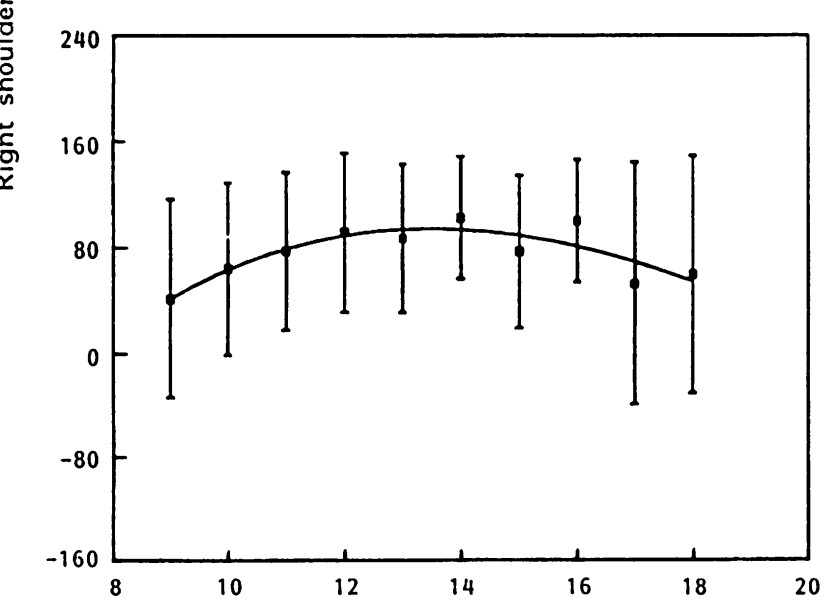

C

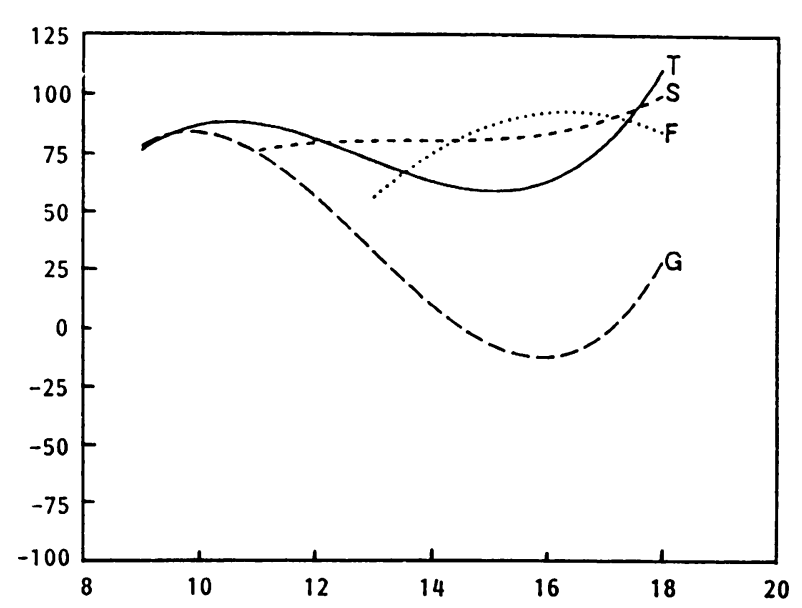

b

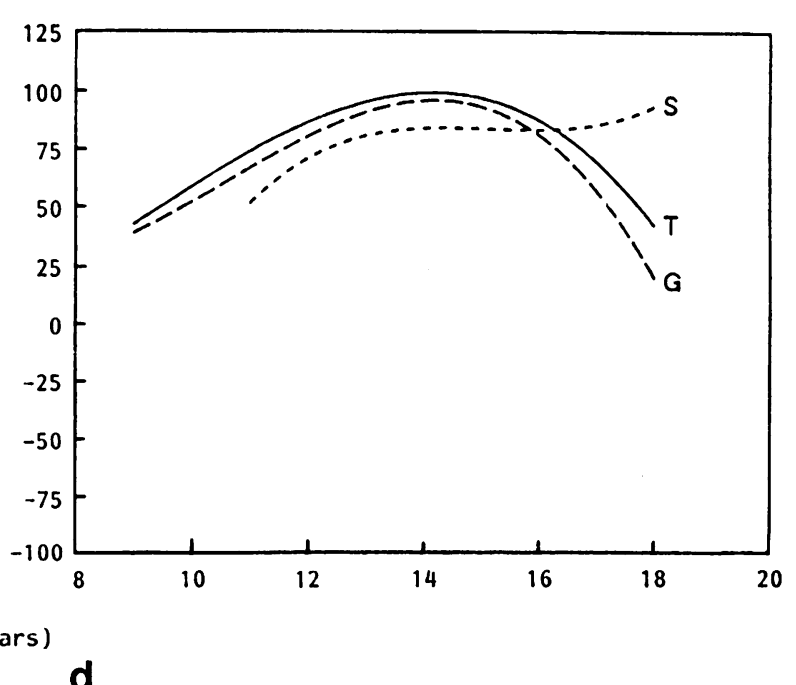

Age (years)

d

Figure 7. Right shoulder flexibility. Values for the left-hand panels are mean(s.d.). The right-hand panels show mean values by sport ( $S$, swimming; $T$, tennis; F, football; G, gymnastics). a boys; b sporting boys; c girls; d sporting girls 


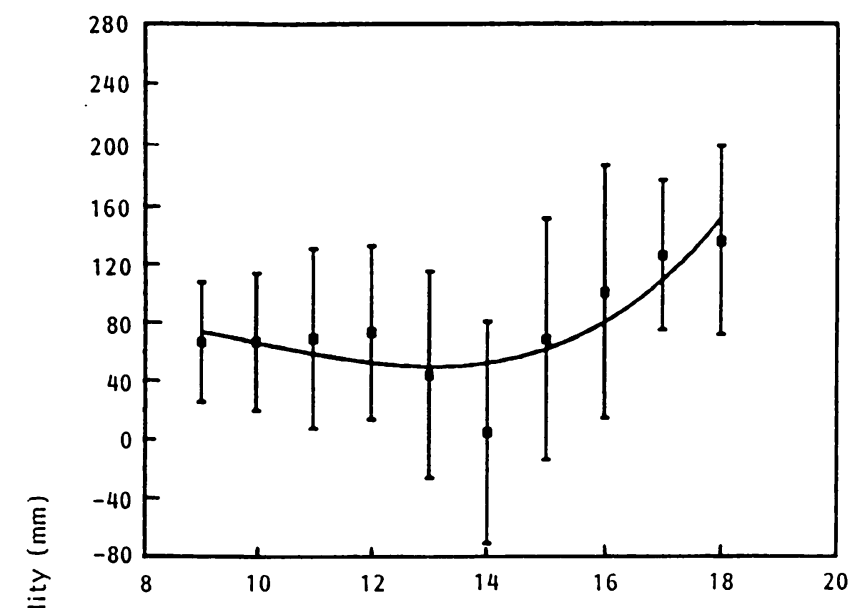

a

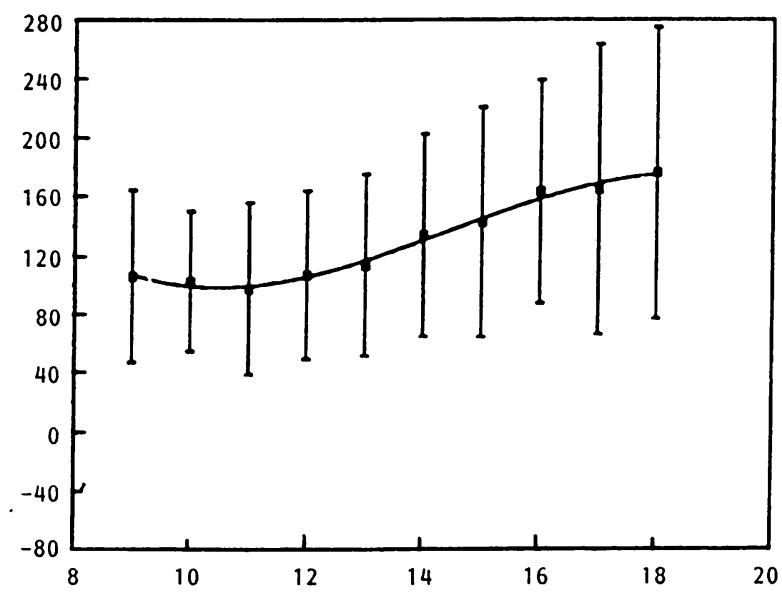

C

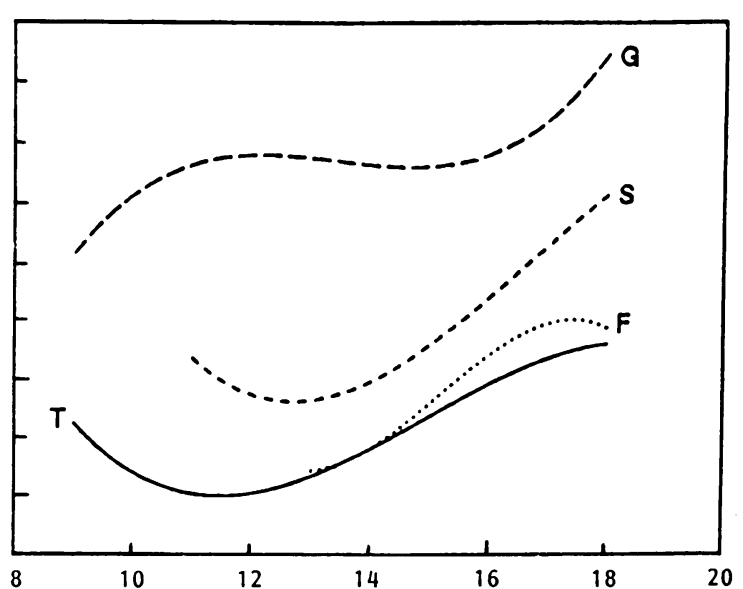

b

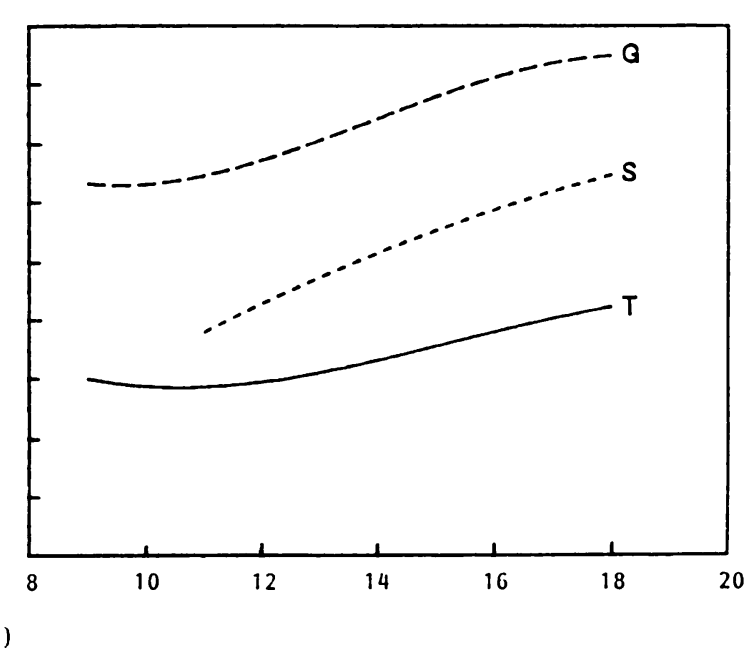

d

Figure 8. Trunk flexibility: average values divided by gender, and by gender and sport. Values for the left-hand panels are mean(s.d.). The right-hand panels show average values by sport. (G, gymnastics; $S$, swimming; $F$, football; $T$, tennis). a boys; b athletic boys; c girls; d athletic girls

gymnasts were the most flexible. Furthermore, they showed much less intersubject variability at all ages.

\section{Flexibility of the hip, adductor muscles and posterior} muscles of the thigh complex

The pattern of hip joint flexibility was similar for girls and boys and, in both sexes and in all sports, it increased with age (Figure 10).

Young gymnasts were significantly more flexible than the children practising other sports from age 14 years (ANOVA; $P=0.0001$ ). When subischial leg length was used as a covariate, gymnasts remained significantly more flexible than the other groups (ANCOVA; $P<0.005$ ).

All measurements of flexibility were strongly correlated in girl swimmers and tennis players. In boys, a poor correlation between glenohumeral and trunk and hip flexibility was evident in all sports, apart from swimmers, in whom all joints were highly correlated with each other.

\section{Strength}

\section{Quadriceps strength}

Boys did not show a decrease in the rate of strength increase by the end of the study, and from 16 years of age were significantly stronger than girls (ANOVA; $P<0.003$ ) (Figure 10). The average maximum isometric quadriceps strength was $13 \%$ greater for boys and $22 \%$ greater for girls than in normal schoolchildren $^{21,26}$ (ANOVA; $P=0.002$ in girls, $P=0.0005$ in boys).

In girls, no significant differences were found among the three sports studied. In boys, 9- and 10 -year-old tennis players were marginally stronger than gymnasts (ANOVA; $P=0.03$ ).

Sport, puberty stage, and height did not exert a significant effect, but age did (ANOVA; $P<0.0001$ ). The athletic girls were significantly stronger at all ages, whereas in boys this difference only became significant above 15 years of age (Figure 10). 

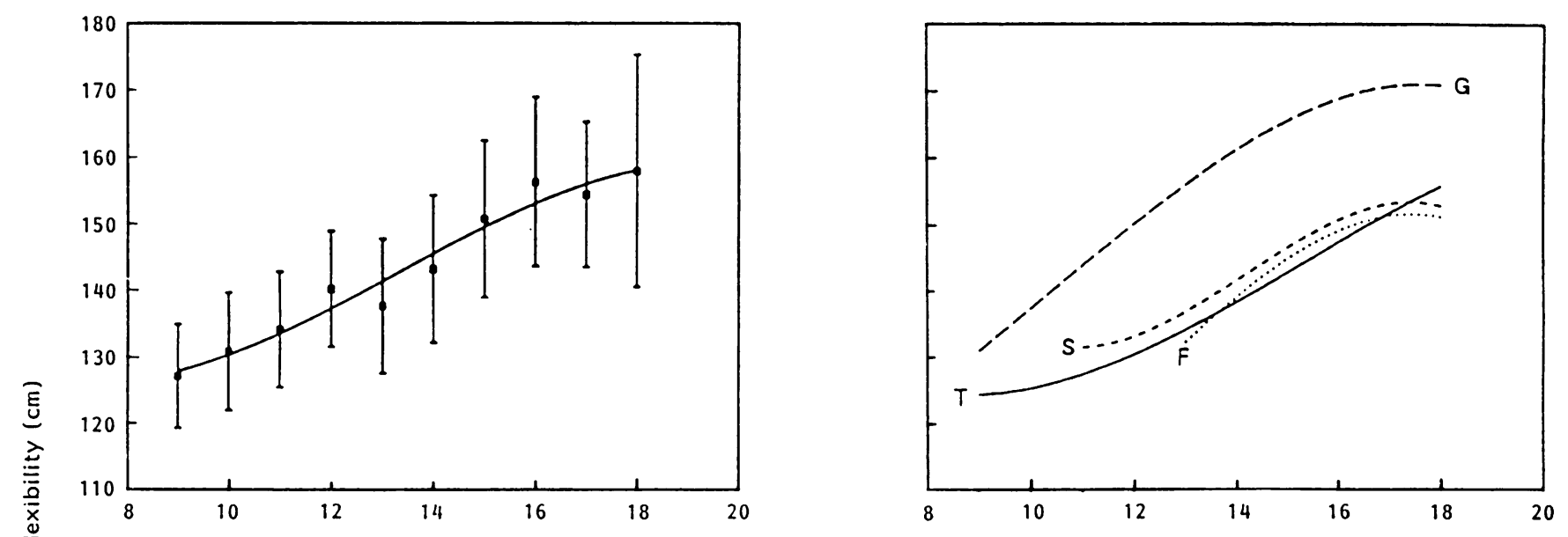

a

b

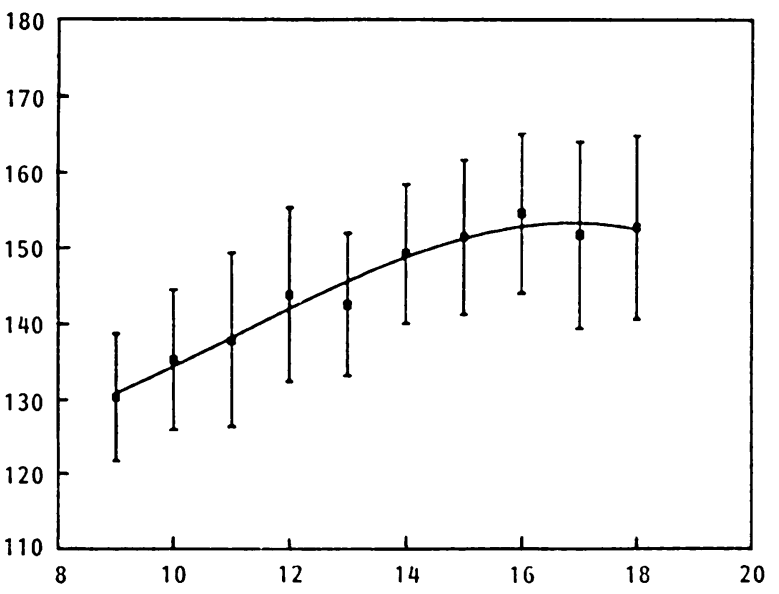

Age (years)

C

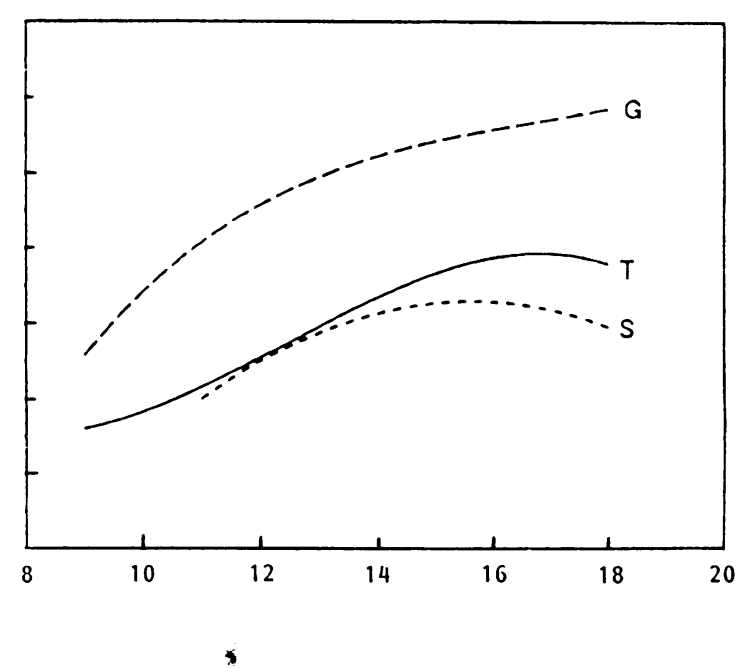

d

Figure 9. Front splits: average values divided by gender, and by gender and sport. Values for the left-hand panels are mean(s.d.). The right-hand panels give average values by sport ( $G$, gymnastics; $T$, tennis; $F$, football; $S$, swimming) a boys; b sporting boys; c girls; d sporting girls

Elbow flexor strength

Isometric strength of the elbow flexors of girls was comparable to that of boys from 9 to 13 years of age, after which time boys increased their strength at a faster rate, the difference becoming significant by the age of 14 years. By the end of the study, boys were stronger than girls by an average of $54 \%$ (Figure 11).

The maximum average strength for the four sports was about $4 \%$ greater for boys and $18 \%$ greater for girls than the bicipital strength in a group of normal schoolchildren ${ }^{26}$.

Sport played, pubertal stage, and height did not exert a significant effect, whereas age did (ANOVA; $P<0.0001)$. Older athletic girls were significantly stronger than nonathletic schoolchildren ${ }^{26}$ (ANOVA; $P=0.03$ ), while the boys remained within their expected limits (Figure 11).

Relationship between muscle strength and body mass In normal children, maximal isometric voluntary strength exerted by the quadriceps is proportional to total body mass ${ }^{21}$. When quadriceps strength was covariated for body mass, boy gymnasts from 11 years of age were consistently stronger than all other athletes (ANCOVA; $P=0.006$ to 0.0001 ). There was no significant difference among the other three sports.

No sports specific differences were noted for girls, although gymnasts and tennis players were significantly less strong at the end of the study than at 9 years (ANCOVA; $P<0.001$ ). Girl swimmers did not show any significant differences between ages 9 to 18 years.

Relationship between biceps strength and CSA of upper arm Isometric strength is proportional to the cross sectional area (CSA) of the muscle ${ }^{45}$. When the data were covariated for CSA of the upper arm, the oldest boys were significantly stronger than the girls (ANCOVA; $P<0.01$ ). Boy gymnasts were the only athletes in which the covariance of the bicipital strength and the CSA of the upper arm increased 


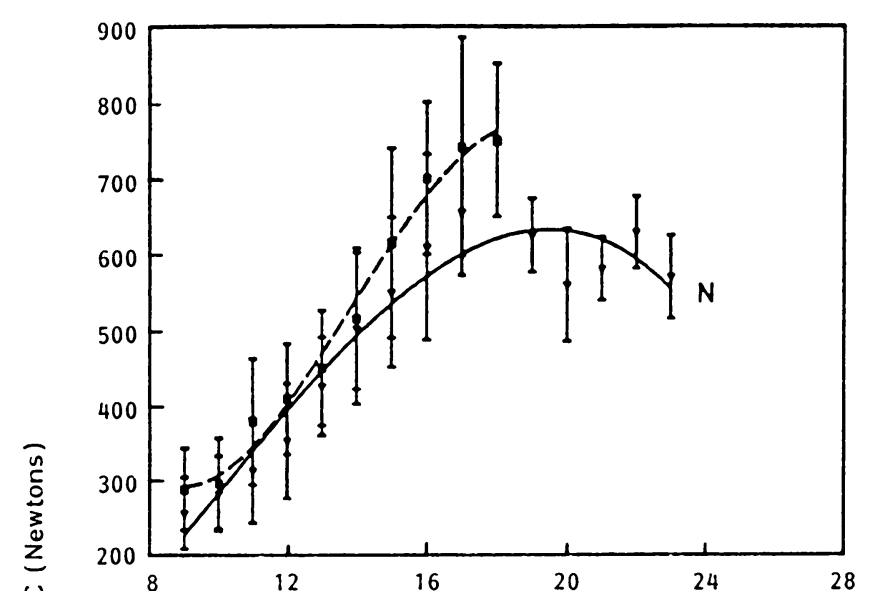

a

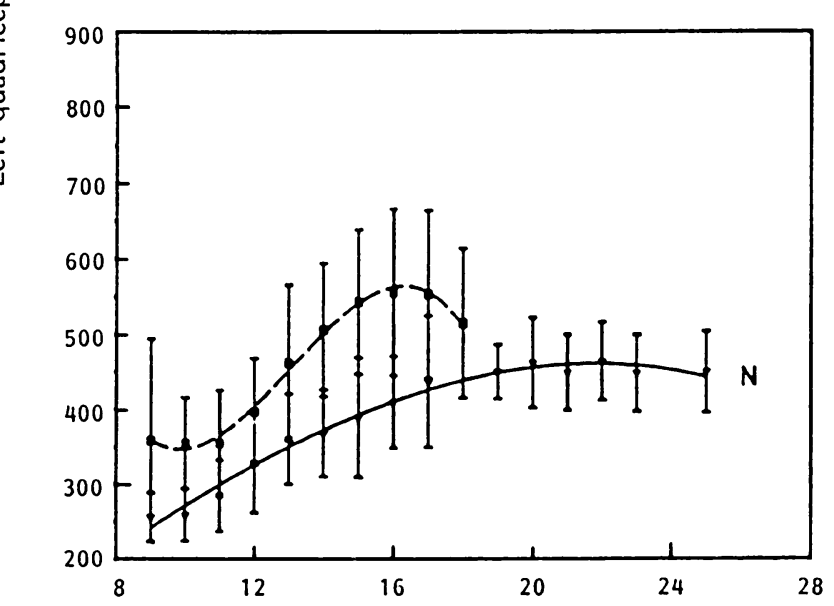

C

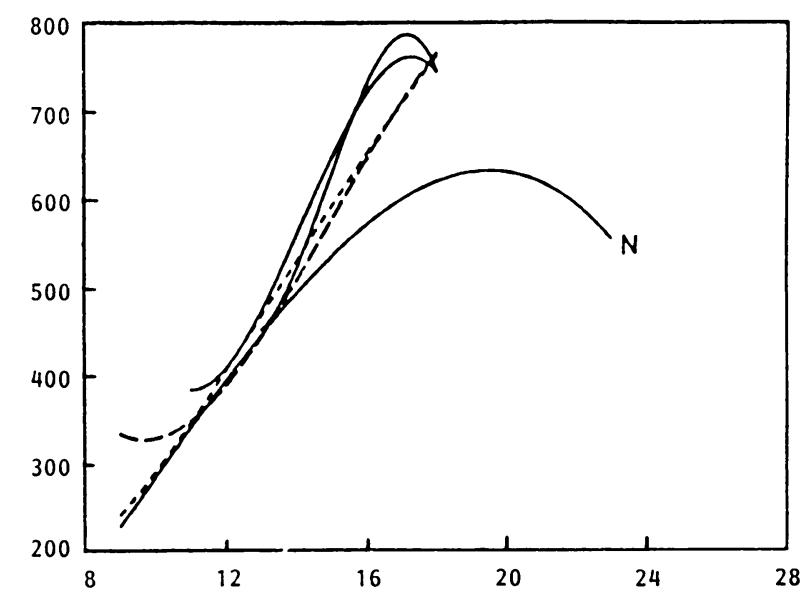

b

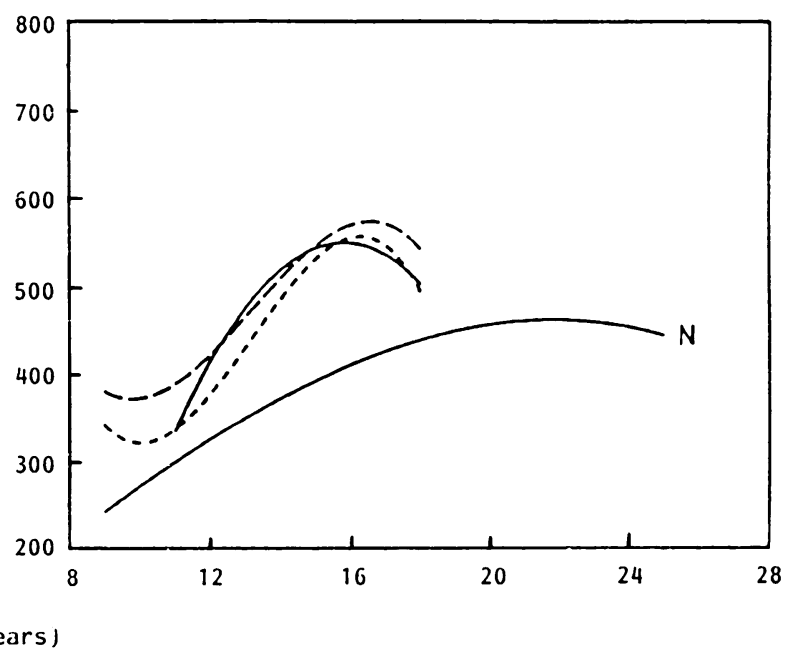

d

Figure 10. Left quadriceps strength: mean values divided by gender, and by gender and sport. On the left panels, values for boys and girls are mean(s.d.). The data on nonathletic children are labelled ' $N$ '. On the right-hand panels, only mean values in boys and girls divided by sport are given. Note the overlapping means and ranges in boys up to age 12 years, with an increasing divergence thereafter, and the higher and broadly parallel increase in girls a boys; b normal and athletic boys; c girls; $\mathbf{d}$ normal and athletic girls

significantly from age 9 to 18 years (ANCOVA; $P<0.005)$.

\section{Discussion}

In the present study, the incidence of injury suffered by boys and girls is similar, except in girl gymnasts in whom it is greater. Comparison of results with these or other studies is difficult given the different definition of 'injury', the level at which the sport is played, the exact definition of the sample studied and the type of study (retrospective or prospective) ${ }^{46}$. A major difference between this study and most of the others performed in this field is that the children who took part in this study were the élite in their particular sport. Therefore, even the youngest age groups had already undergone a rigorous selection process, and had already been training for some years. To continue the hard training routines they undergo, they must be especially gifted. Their musculoskeletal system, for example, could be particularly resistant to external trauma. Also, their body awareness may be genetically better developed than in 'normal' children, thus decreasing the risks of some injuries due to, for example, overbalancing.

A recent prospective study of 496 young Danish footballers aged 12 to 18 years, using a definition of injury similar to the one adopted here, showed an incidence of only 3.7 injuries per $1000 \mathrm{~h}$ of soccer played ${ }^{47}$. The incidence increased with age, and, in the older children, approximated the incidence rate of senior players ${ }^{47}$. A direct comparison with our data is not, however, feasible, given the different structure of the sport in Denmark, and the criteria used in the selection of the sample. However, young Danish soccer players suffer from up to approximately 30 times fewer injuries than their English counterparts.

Athletic ability is to a large extent genetically determined and it is possible that these children were 

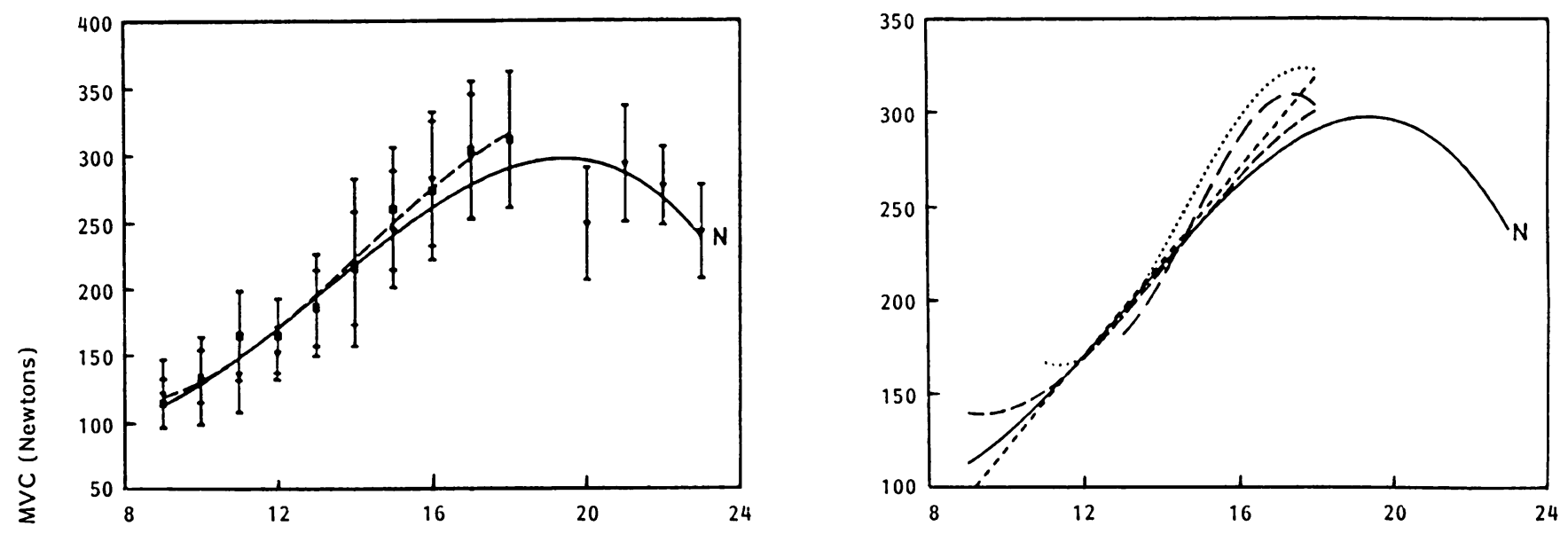

a

b

Figure 11. Left elbow flexors strength: average values divided by gender, and by gender and sport. On the left-hand panels, the values for boys and girls are mean(s.d.). The data on nonathletic children are labelled ' $N$ '. On the right-hand panels, only mean values in boys and girls divided by sport are given. Note the same general features as in Figure 10, but the smaller absolute and relative differences between trained and untrained children a boys, $b$ normal and athletic boys; c girls; d normal and athletic girls

genetically endowed with a more resistant musculoskeletal system ${ }^{48}$.

The present study suggests that some ranges of motion are sports specific, and that most of them are influenced by age. The ability to perform better at splits is commonly perceived as a major feature of gymnastics. However, given the wide variability in the children's ability at this particular exercise, the differences between the four sports were not statistically significant up to 14 years of age. On the other hand, the trunk forward bending test may be more specific in this respect.

An intrinsic limitation of the tests performed is that they express linear rather than angular measures. In future, angular measures should probably be employed, keeping in mind that even these could underestimate the flexibility of the hip in gymnasts. The differences in body proportions among participants in the various sports should be considered when evaluating flexibility. This was particularly evident in gymnasts, as, when corrections were made for the relevant anthropometric values, the degree of trunk flexibility became even more evident.

In girls, flexibility appeared to be more generalized than in boys, in whom flexibility of the upper body was independent of that of the lower body. The relationship between the flexibility of the various joints varied with time. Training may have been progressively directed towards the development of hip joint rather than trunk flexibility. Alternatively, trunk flexibility may naturally develop before hip joint flexibility, and, in gymnasts, trunk flexibility may have already been maximally developed in the first year of the study, leaving room for improvement only in the hip joint.

Flexibility in young athletes appears to be jointspecific, in contrast to the generalized laxity exhibited in some medical conditions. 
Athletic girls in their late teens were only slightly less strong than nonathletic boys ${ }^{26}$. These differences could be explained by the effects of training, genetic predisposition or a combination of these two factors. Several factors other than increase in body dimensions influence muscle strength and power output. Our findings of a significant influence of age but not of pubertal status and height concur with the data of Sargeant and Dolan ${ }^{49}$ who reported a large increase in power output from childhood to adulthood, even when standardized for muscle volume.

Changes in the intrinsic qualities of the muscle tissue with maturation play a significant role in strength development. Other reasons for this increase include changes in fibre type composition, in intramuscular fat, in the lever system through which a muscle acts, and in the angle of pennation of the muscle fibres ${ }^{50}$.

The additional effects of training are still unclear, although our data suggest that there may be sports specific effects which could be different in boys and girls. The possible influence of testosterone on muscular strength seems to have a preferential effect on the upper body musculature ${ }^{21}$, and it was of interest that the proportional differences between the sexes was greatest for the elbow flexors (Figures 10 and 11).

Increase in muscular strength can be induced by low-repetition high-force exercises ${ }^{51}$. Heavy resistance training may produce skeletal muscle hypertrophy ${ }^{52}$. A greater strength relative to muscle CSA was evident in boy gymnasts in the present study.

Given the nature of each sport, it is likely that different loads were imposed on the muscle groups assessed. For example, although footballers often practise weight-training, they mainly use their lower limbs in their sport. Gymnasts make their upper limbs weight-bearing, imposing on them a variety of eccentric and concentric loads, and swimmers are obliged by the medium in which they train to undergo a kind of continuous isokinetic muscle contraction $^{48}$. These different requirements imply a different pattern of activity with different neuromuscular activation ${ }^{48}$, eventually resulting in different neural adaptation ${ }^{53}$.

Boys and girls in all sports were of similar strength up to around 11 years, after which boys increased their strength overtaking girls between the ages of 12 to 14 years. Isometric muscle strength continues to increase up to 20 years of age in nonathletic subjects $^{26}$, and, although we were unable to ascertain whether this was also true for athletes, values in boys were still rising at the age of 18 years, in contrast to girls in whom a plateau or slight decline was observed (Figures 10 and 11).

\section{Acknowledgements}

This study, called the Training of Young Athletes (TOYA) Study was supported by a grant from the Sports Council, England. We thank Drs David Jones and Dawn F. Parker who allowed us to use the isometric strength data they collected on nonathletic individuals.

\section{References}

1 Maffulli N, Pintore E. Intensive training in young athletes. $\mathrm{Br}$ J Sports Med 1990; 24: 237-9.

2 Maffulli $N$. Intensive training in young athletes. The orthopaedic surgeon's view point. Sports Med 1990; 9: 229-43.

3 Maffulli N, Helms P. Controversies about intensive training in young athletes. Arch Dis Child 1988; 63: 1405-7.

4 Gallagher SS, Finison K, Guyer B, Goodenough S. The incidence of injuries among 87,000 Massachusetts children and adolescents: results of the 1980-81 Statewide Childhood Injury Prevention Program Surveillance System. Am J Public Health 1984; 8: 318-24.

5 Zaricznyj B, Shattuck LJM, Mast TA, Robertson RV, D'Elia G. Sports-related injuries in school-aged children. Am J Sports Med 1980; 8: 318-24.

6 Beaty JH. Sports related injuries in children and adolescents. Ann Sports Med 1987; 3: 97-9.

7 Lysens $R$, Steverlynck $A$, van den Auweele $Y$ et al. The predictability of sports injuries. Sports Med 1984; 1: 6-10.

8 Cureton TK. Flexibility as an aspect of physical fitness. Res Quaitt 1941; 12: 381-390.

9 Dubs L, Gschwend N. General joint laxity. Quantification and clinical relevance. Arch Orthop Trauma Surg 1988; 107: 65-72.

10 Carter C, Wilkinson J. Persistent joint laxity and congenital dislocation of the hip. I Bone Joint Surg [Br] 1964; 46-B: 40-5.

11 Wynne-Davies, R. Acetabular dysplasia and familial joint laxity: two aetiological factors in congenital dislocation of the hip. J Bone Joint Surg [Br] 1970; 52-B: 704-6.

12 Fairbank JCT, Pynsent PB, Van Pootvielt JAV, Phillips H. Influence of anthropometric factors and joint laxity in the incidence of adolescent back pain. Spine 1984; 9: 461-4.

13 Grana WA, Moretz JA. Ligamentous laxity in secondary school athletes. J Am Med Ass 1978; 240: 1975.

14 Jackson DW, Jarret H, Bailey D, Kausek J, Swanson J, Powell JW. Injury prediction in the young athlete: a preliminary report. Am J Sports Med 1978; 6: 6-14.

15 Reid DC, Burnham RS, Saboe LA, Kushner SF. Lower extremity flexibility patterns in classical ballet dancers and its correlation to lateral hip and knee injuries. Am I Sports Med 1987; 15: 347-52

16 Chandler TJ, Kibler WB, Uhl TL, Wooten B, Kiser A, Stone E. Flexibility comparisons of junior elite tennis players to other athletes. Am J Sports Med 1990; 18: 134-6.

17 Tanner JM. Growth at adolescence, 2nd ed. Oxford, UK: Blackwell Scientific Publications, 1962.

18 Pratt M. Strength, flexibility, and maturity in adolescent athletes. Am J Dis Child 1989; 143: 560-3.

19 Backman E. Methods for measurement of muscle function. Methodological aspects, reference values for children, and clinical evaluation. Scand I Rehabil Med 1988; 20(Suppl): 1-95.

20 Backman $E$, Odenrick $P$, Henriksson KG, Ledin T. Isometric muscle force and anthropometric values in normal children aged between 3.5 and 15 years. Scand I Rehabil Med 1989; 21: 105-14.

21 Parker DF. Factors controlling the development and strength of human skeletal muscle. London, UK: PhD Thesis, 1989.

22 Jones HE. Motor performance and growth. A developmental study of static dynamometric strength. Berkeley, California, USA: University of California Press, 1949.

23 Andersen LB, Henckel P. Maximal voluntary isometric strength in Danish adolescents 16-19 years of age. Eur J Appl Physiol 1987; 56: 83-9.

24 Asmussen E, Heebohl-Nielsen KR. A dimensional analysis of performance and growth in boys. J Appl Physiol 1954; 7: 593-603.

25 Davies CTM. Strength and mechanical properties of muscle in children and young adults. Scand I Sports Sci 1985; 7: 11-15.

26 Parker DF, Round JM, Sacco P, Jones DA. A cross-sectional survey of upper and lower limb strength in boys and girls during childhood and adolescence. Ann Human Biol 1990; 17: 199-211.

27 Tanner JM, Whitehouse RH. Growth and development record. Boys: birth-19 years. Triceps and subscapular skinfolds. Ware, UK: Castlemead Publications, 1985.

28 Tanner JM, Whitehouse RH. Growth and development record. Girls: birth-19 years. Triceps and subscapular skinfolds. Ware, UK: Castlemead Publications, 1985. 
29 Tanner JM, Whitehouse RH. Clinical longitudinal standards for height, weight, height velocity, weight velocity and stages of puberty. Arch Dis Child 1976; 51: 170-9.

30 Tanner JM, Whitehouse RH. Growth and development record. Boys: birth-19 years. Height and weight. Castlemead Publications, Crane Mead Ware, 1983.

31 Tanner JM, Whitehouse RH. Growth and development record. Girls: birth-19 years. Height and weight. Ware, UK: Castlemead Publications, 1983.

32 Durnin JVGA, Rahaman HH. The assessment of the amount of fat in the human body from measurements of skinfold thickness. Br J Nutr 1967; 21: 681-9.

33 Durnin JVGA, Womersley J. Body fat assessed from total body density and its estimation from skinfold thickness: measurements on 481 men and women aged 16 to 72 years. $\mathrm{Br}$ J Nutr 1974; 32: 77-97.

34 de Koning FL, Binkhorst RA, Kauer JMG, Thijssen HOM. Accuracy of an anthropometric estimate of the muscle and bone area in a transversal cross-section of the arm. Int J Sports Med 1986; 7: 246-9.

35 Nilsson S. Jogging injuries. An overview. Scand J Soc Med 1982; 29(Suppl); 171-8.

36 Koch BM, Galioto FM, Vaccaro P, Vaccaro J, Buckenmeyer PJ. Flexibility and strength measures in children participating in a cardiac rehabilitation exercise program. Physician and Sportsmedicine 1988; 16: 139-47.

37 Broer $M$, Galles N. Importance of relationship between various body measurements in performance of the toe-touch test. Res Quart 1958; 29: 253-65.

38 Wiklander J, Lysholm J. Simple tests for surveying muscle strength and muscle stiffness in sportsmen. Int J Sports Med 1987; 8: 50-4.

39 Cameron N. The measurement of human growth. Beckenham, UK: Croom Helm 1994.

40 Davies J, Parker DF, Rutherford OM, Jones DA. Changes in strength and cross-sectional area of the elbow flexors as a result of isometric strength training. Eur J Physiol 1988; 57: 667-70.
41 Rutherford OM, Jones DA, Newham DJ. Clinical and experimental application of the percutaneous twitch superimposition technique for the study of human muscle activation. I Neurol Neurosurg Psychiatr 1986; 49: 1288-91.

42 Joyner SP. SAS/STAT guide for personal computers, Version 6 edition. Cary, North Carolina, USA: SAS Institute, 1985.

43 Leland W. SYSTAT: the system for statistics. Evanston, Illinois, USA: SYSTAT, 1988: 1-959.

44 Tanner JM. Fallacy or per-weight and per-surface area standards and their relation to spurious correlation. $J$ Appl Physiol 1949; 2: 1-15.

45 Maughan RJ. Relationship between muscle strength and muscle cross-sectional area. Implications for training. Sports Med 1984; 1: 263-74.

46 Yde J, Nielsen AB. Sports injuries in adolescents' ball games: soccer, handball and basketball. Br J Sports Med 1990; 24: 51-4.

47 Schmidt-Olsen S, Jorgensen $U$, Kaalund $S$, Sorensen J. Injuries among young soccer players. Am J Sports Med 1991; 19: 273-5.

48 Astrand P-O, Rodahl K. Textbook of Work Physiology, 3rd ed. New York, USA: McGraw-Hill International Editions, 1986.

49 Sargeant AJ, Dolan P. Optimal velocity of muscle contraction for short term (anaerobic) power output in children and adults. In: Rutefranz J, Mocellin R, Klimt F, eds. Children and Exercise XII. Champaign, Illinois, USA: Human Kinetics, 1986: 39-42.

50 Jones DA, Rutherford OM, Parker DF. Physiological changes in skeletal muscle as a result of strength training. Quart J Exper Physiol 1989; 74: 233-56.

51 DeLorme TL. Restoration of muscle power by heavy resistance training. J Bone Joint Surg [Am] 1945; 27-A: 645-67.

52 Sale DG, MacDougall JD, Alway SE, Sutton JR. Voluntary strength and muscle characteristrics in untrained men and women and male bodybuilders. J Appl Physiol 1987; 62: 1786-93.

53 Moritani T, deVries HA. Neural factors versus hypertrophy in the time course of muscle gain. Am J Phys Med 1979; 58: $115-30$.
This Conference will offer a broadly-based broadlydirected overview of the Prevention, Recognition and Management of Ski-Related Disorders arising in British patients who have encountered resort-based problems.

It is aimed at Consultant Orthopaedic Surgeons and

Senior Orthopaedic Registrars. It is also open to

Doctors, Physiotherapists and Paramedics with an involvement in the trauma of skiing.
Covering $1 \frac{1}{2}$ days, this intensive conference takes place at the same time as the Daily Mail Ski Show, and each delegate receives a free ticket to this show.

A fully descriptive brochure is available, which describes the scientific programme and lists the speakers. A full residential package is offered, with a course dimner and additional nights - all as optional extras.

\section{MetaPhor Conferences}

